\title{
URINARY MORPHINE EXCRETION DURING AND AFTER MORPHINE ANAESTHESIA FOR OPEN-HEART SURGERY IN CHILDREN
}

\author{
Theodore H. Stanley and George D. Lathrop
}

Although LaRge Doses of MoRPhine $(0.5-4.0 \mathrm{mg} / \mathrm{kg}$ ) and oxygen has become a popular anaesthetic technique for patients undergoing open-heart surgery, the fate of these doses of morphine has not been investigated. In this study urine was analyzed for morphine and its glucuronide conjugation product before, during and after atrial septal defect (ASD) or tetralogy of Fallot (TF) repairs in children anaesthetized with morphine 1 to $4 \mathrm{mg} / \mathrm{kg}$ plus oxygen.

\section{METHODS}

A total of 20 children, 6-12 years of age, who were not receiving any cardiac medications or diuretics and who were scheduled to undergo complete correction of ASD of the secundum type or TF, served as the subjects for the investigations. Five of the nine TF patients had had a previous subclavian to pulmonary artery anastomosis operation. The remaining TF patients and all eleven ASD patients had never been operated on before.

Premedication consisted of pentobarbitone $1 \mathrm{mg} / \mathrm{kg}$ body weight and atropine $0.005 \mathrm{mg} / \mathrm{kg}$ given 90 minutes prior to the operation. A bladder catheter was implanted at the time of premedication and urine was collected from then until anaesthesia was begun. Urine was also collected during anaesthetic induction, throughout the entire operation and for two hours post-operatively. Urine was analyzed for morphine and its glucuronide conjugation product by electron capture gas-liquid chromatography. ${ }^{1}$

Before anaesthesia was begun or after anaesthetic induction, two intravenous catheters were implanted in the upper extremities; a central venous pressure catheter was placed either into the basilic vein in the antecubital fossa or into the internal jugular vein in the neck and threaded to the right atrium and a radial or brachial artery catheter was introduced. Mean arterial blood pressure was recorded every five minutes during induction, during the entire operative procedure, and for the first 12 hours post-operatively. Standard electrocardiographic leads were applied to the extremities. Anaesthesia was induced with intravenous morphine given at a rate of $5-15 \mathrm{mg} / \mathrm{min}$ while the patient breathed 100 per cent

Theodore H. Stanley, M.D., Associate Professor Anesthesiology/Surgery, University of Utah College of Medicine.

George D. Lathrop, Ph.D., Chief, Epidemiology Division, Brooks Air Force Base.

From the Department of Anesthesiology, The University of Utah College of Medicine, Salt Lake City, Utah 84132 and the Epidemiology Division, Brooks Air Force Base, San Antonio, Texas 78235 .

Presented at the 1976 Annual Meeting of the Canadian Anaesthetist Society in Montreal, Canada, June 1976. 
oxygen. Respirations were first assisted and then controlled to keep arterial $\mathrm{P}_{\mathrm{CO}_{2}}$ $\left(\mathrm{Pa}_{\mathrm{CO}_{2}}\right)$ between 34 and 40 torr. Arterial blood samples for blood gas analysis were obtained every 15 minutes. Following loss of consciousness patients were paralyzed with succinylcholine $1.5 \mathrm{mg} / \mathrm{kg}$ and had their tracheas intubated. Controlled ventilation was continued. When succinylcholine paralysis disappeared, patients were given d-tubocurarine 0.3 to $0.5 \mathrm{mg} / \mathrm{kg}$ over a period of 20 minutes and the operation was started. If additional anaesthesia was considered necessary during the operation 2 to $5 \mathrm{mg}$ supplements of morphine were administered.

Lactated Ringer's solution with 5 per cent dextrose was administered at a rate of $10-15 \mathrm{mg} / \mathrm{kg} / \mathrm{hr}$ during induction of anaesthesia and $1-2 \mathrm{mg} / \mathrm{kg} / \mathrm{hr}$ during the operation. Post-operatively, lactated Ringer's solution was administered at a rate of 1 to $3 \mathrm{mg} / \mathrm{kg} / \mathrm{hr}$. Whole blood was the only colloid given routinely during operation and in the first two post-operative hours. During bypass, blood was added to the oxygenator as required to maintain a blood flow of at least $60 \mathrm{ml} / \mathrm{kg} / \mathrm{min}$. After bypass and in the recovery room, blood was given to maintain pre-operative central venous or intra-operative left atrial pressures. Blood loss was estimated by measuring suction drainage and by weighing sponges during operation and by measuring chest tube drainage post-operatively.

The extracorporeal system consisting of Bentley oxygenator and Sarns roller pump was primed with 18 to $24 \mathrm{ml} / \mathrm{kg}$ of fresh heparinized whole blood and 30 to $40 \mathrm{mg} / \mathrm{kg}$ of lactated Ringer's solution. Samples of mixed venous blood were obtained at the venous inflow to the oxygenator every 15 minutes and analyzed on a Radiometer acid-base analyzer for $\mathrm{P}_{\mathrm{O}_{2}}, \mathrm{P}_{\mathrm{C}_{2}}$ and $\mathrm{pH}$. Bypass flows were maintained between 60 and $100 \mathrm{ml} / \mathrm{kg} / \mathrm{min}$ in order to keep mixed venous oxygen tension between 38 and 42 torr. Mean blood pressure and extracorporeal flow rate were recorded every 5 minutes during bypass. Oesophageal temperature was monitored during operation with a Yellow Springs temperature probe. Patients were cooled to $32^{\circ} \mathrm{C}$ during bypass and rewarmed to $37^{\circ} \mathrm{C}$ at its conclusion. Temperature corrections were made for blood gas analysis of specimens obtained during hypothermia, using standard nomograms. At the conclusion of bypass, calcium chloride 100 to $600 \mathrm{mg}$ was given routinely. No other inotropic agents were needed during the operative period.

Muscle relaxants were not used during the last two to three hours of the operation. All patients could sustain a 30 Hertz tetanic stimulus administered by a Burroughs Wellcome Block-aide monitor to the ulnar nerve at the wrist without fade, two hours after the operation.

Post-operatively the children were given 100 per cent oxygen to breathe and ventilation was assisted or controlled to keep $\mathrm{Pa}_{\mathrm{CO}_{2}}$ at 38 to 44 torr for two hours. Thereafter every two hours each patient was placed on a T-piece set-up with 7-15 litres/min of 100 per cent oxygen and allowed to breathe spontaneously without mechanical assistance for 20 minutes. Arterial blood samples were analyzed for $\mathrm{Pa}_{\mathrm{CO}_{2}}$ every five minutes. If $\mathrm{Pa}_{\mathrm{CO}_{2}}$ remained $<50$ torr for 20 minutes spontaneous ventilation was continued with an inspired oxygen concentration which was sufficient to maintain arterial $\mathrm{P}_{\mathrm{O}_{2}}\left(\mathrm{~Pa}_{\mathrm{O}_{2}}\right)$ higher than 100 torr. If $\mathrm{PaCO}_{2}$ was maintained less than 50 torr and $\mathrm{Pa}_{\mathrm{O}_{2}}$ above 100 torr with an inspired oxygen concentration of 40 per cent or less for two hours, extubation was considered. Extubation was ac- 
complished when, in addition to maintaining these blood gas tensions, each patient could sustain a tidal volume more than $5 \mathrm{ml} / \mathrm{kg}$ and vital capacity greater than $15 \mathrm{mg} / \mathrm{kg}$ as measured by a Wright spirometer attached to the tracheal tube and when arterial blood pressure had not changed by more than 15 per cent in the preceding hour.

No patient received a narcotic antagonist during the operation or post-operatively. Only patients who did not require inotropic, analgesic or diuretic drugs during the first 12 post-operative hours and who had an average urine output $>20 \mathrm{ml} /$ hour and mean blood pressure $>65$ torr were allowed to remain in the study protocol.

\section{REsults}

The mean age of both groups of patients was similar (Table I). However, ASD patients were significantly heavier $(P<0.05)$ than those with TF. Children with ASD received an average of $3.4 \mathrm{mg} / \mathrm{kg}$ of morphine while those with $\mathrm{TF}$ required an average of $2.9 \mathrm{mg} / \mathrm{kg}$.

Pre-operative, induction and post-operative mean arterial blood pressures were similar in both groups; however, children with ASD had significantly higher blood pressures throughout the entire operation than children with $\mathrm{TF}(\mathrm{P}<0.05)$, (Table II). Extracorporeal flow rates were significantly higher $(\mathrm{P}<0.05)$ and time of bypass and total operative time slightly longer $(P<0.05)$ in TF patients than those with ASD (Table III). TF patients received similar volumes of crystalloid (lactated Ringer's in 5 per cent dextrose and water) but significantly greater amounts of blood during operation than ASD patients $(\mathrm{P}<0.05)$. TF patients also lost more blood during operation than ASD patients (Table IV). Blood loss and crystalloid and blood administration were similar in both groups during the first two postoperative hours.

Mean urine output, urine flow rate, per cent of urinary morphine in the glucuronide form and cumulated per cent of administered morphine excreted in urine appear in Table $V$. Children with ASD had a higher $(P<0.01)$ mean urine flow rate during anaesthetic induction and during the entire operation than those with TF. The former also sustained significant increases in urinary output and flow rate during induction and operation when compared to pre-operative valves. Children with ASD excreted a greater percentage of the administered morphine by the time they reached the recovery room ( 54 per cent versus 29 per cent) and after two hours in the recovery room (59 per cent versus 33 per cent) than children with TF. Urinary morphine in the glucuronide form increased progressively from induction until the post-operative period in both groups and was more than 85 per cent in all patients at the end of the operation and more than 93 per cent after two hours in the recovery room. Means of $11.2 \pm 1.8$ per cent and 6.0 \pm 1.1 per cent of administered morphine were excreted unchanged in the urine after two post-operative hours in ASD and TF patients, respectively.

Six of the eleven ASD patients in the study had respiratory dynamics that enabled them to be extubated between the fourth and sixth post-operative hours. Those that could be extubated before six hours in the recovery room had received a 
STANLEY \& LATHROP: URINARY MORPHINE EXCRETION

TABLE I

Preoperative Data (Mean \pm SD)

\begin{tabular}{lcccc}
\hline \hline & $\begin{array}{c}\text { Number of } \\
\text { patients }\end{array}$ & $\begin{array}{c}\text { Age } \\
\text { (years) }\end{array}$ & $\begin{array}{c}\text { Weight } \\
(\mathrm{kg})\end{array}$ & $\begin{array}{c}\text { Administered } \\
\text { morphine } \\
(\mathrm{mg} / \mathrm{kg})\end{array}$ \\
\hline ASD & 11 & 8.2 & 38.7 & 3.4 \\
& & \pm 2.1 & \pm 4.4 & \pm 0.9 \\
TF & 9 & 9.1 & $27.6^{*}$ & 2.9 \\
& & \pm 1.5 & \pm 4.7 & \pm 0.8 \\
\hline
\end{tabular}

${ }^{*} \mathrm{P}<0.05$, Student's unpaired t-test when compared to children with ASD.

TABLE II

Mean Arterial Blood Pressure in Torr (Average \pm SD)

\begin{tabular}{lcccc}
\hline \hline & Pre-operative & Induction & Operative & Post-operative \\
\hline \multirow{2}{*}{ ASD } & 85 & 86 & 88 & 83 \\
& \pm 12 & \pm 9 & \pm 13 & \pm 10 \\
TF & 80 & 81 & $72^{*}$ & 82 \\
& \pm 10 & \pm 11 & \pm 16 & \pm 9 \\
\hline
\end{tabular}

${ }^{*} \mathrm{P}<0.05$, Student's unpaired t-test when compared to children with ASD.

TABLE III

Intraoperative and Bypass Time and Flow Data (Mean \pm SD)

\begin{tabular}{lccc}
\hline \hline & $\begin{array}{c}\text { Length of } \\
\text { procedure (hr) }\end{array}$ & $\begin{array}{c}\text { Time of } \\
\text { bypass min) }\end{array}$ & $\begin{array}{c}\text { Bypass flow } \\
(\mathrm{ml} / \mathrm{kg})\end{array}$ \\
\hline ASD & 3.8 & 37 & 65 \\
TF & \pm 0.6 & \pm 10 & \pm 9 \\
& $5.4^{*}$ & $72^{*}$ & $87^{*}$ \\
\hline
\end{tabular}
ASD.

TABLE IV

Intraoperative Blood Loss, Crystalloid Administration and Blood Replacement Data (Mean $\pm \mathrm{SD}$ )

\begin{tabular}{lccc}
\hline \hline & $\begin{array}{c}\text { Blood } \\
\text { loss } \\
(\mathrm{ml})\end{array}$ & $\begin{array}{c}\text { Blood } \\
\text { replacement } \\
(\mathrm{ml})\end{array}$ & $\begin{array}{c}\text { Crystalloid } \\
\text { administered } \\
(\mathrm{ml})\end{array}$ \\
\hline $\mathrm{ASD}$ & 453 & 601 & 672 \\
$\mathrm{TF}$ & \pm 172 & \pm 203 & \pm 54 \\
& $1301^{*}$ & $1487^{*}$ & 731 \\
\hline 281 & \pm 361 & \pm 43 \\
\hline
\end{tabular}

${ }^{*} \mathrm{P}<0.05$, Student's unpaired t-test when compared to children with ASD. 


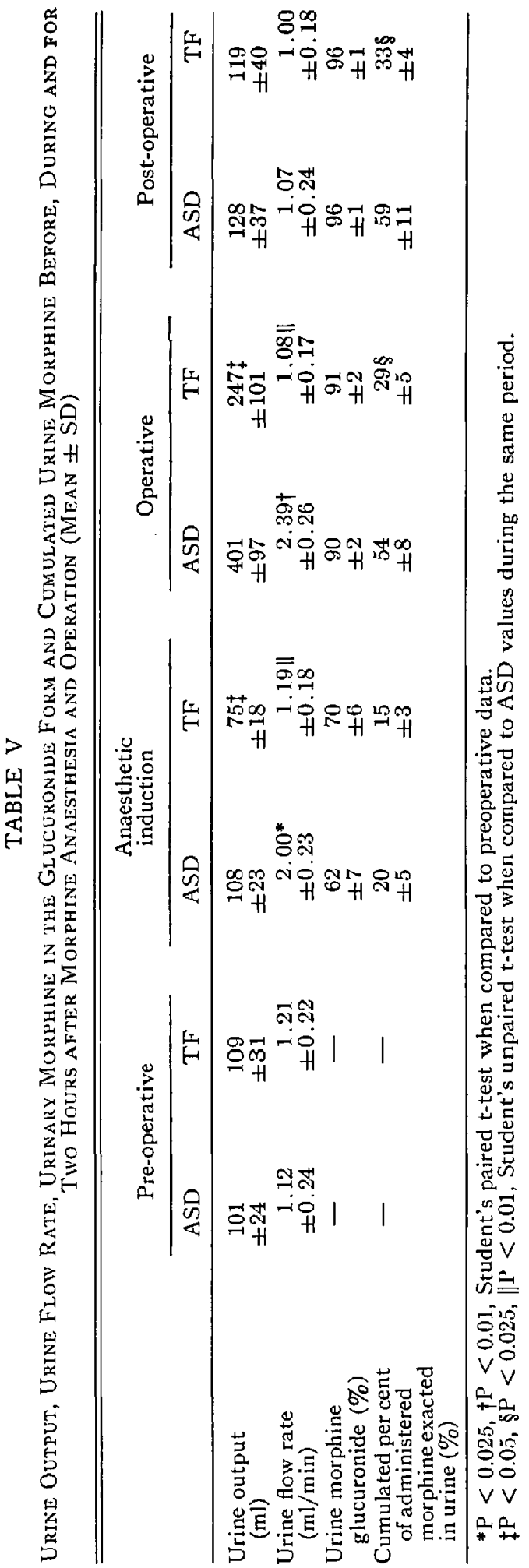


similar amount of morphine and had lost and had had replaced a similar volume of blood as those that could not be extubated. However, the former had a higher $(\mathrm{P}<0.05)$ urine output and excreted a significantly greater percentage $(\mathrm{P}<0.025)$ of administered morphine ( 68 per cent versus 51 per cent) after two hours in the recovery room than the latter. None of the children with TF could be extubated until the morning after their operation.

\section{Discussion}

Studies in morphine addicted man have demonstrated that 75 to 90 per cent of the opiate is excreted in the urine in its free form or as morphine-3-glucuronide within 24 hours of its subcutaneous administration. ${ }^{2,3}$ These investigations have also shown that only 10 per cent of the administered drug remains unchanged and that excretion of total drug administered is linearly related to the volume of the daily urine output. Our findings in this study in non-addicted children receiving large doses of intravenous morphine for anaesthesia document that the majority of the opiate is excreted as the glucuronide conjugation product and that the proportion of morphine excreted in this form increases with time after administration. In addition, our data suggest that, as in the narcotic addict, patients having a higher urine output after receiving anaesthetic doses of morphine excrete more of the opiate and have less depression of respiratory dynamics post-operatively than those with a lower urine output.

The mechanism of greater urine output in patients with ASD than in those with TF during anaesthesia and open-heart operation is unknown. In a recent study we demonstrated that this occurs at apparently equal depths of anaesthesia, irrespective of whether the primary anaesthetic is morphine or halothane and whether or not urinary norepinephrine excretion is increased. The results of our previous investigation suggested that patients with ASD or TF and higher urine outputs tended to have higher mean arterial blood pressures than similar patients with lower urine outputs. We speculated that one reason for this could be that morphine excretion was greater in the former groups and this resulted in lower circulating morphine concentrations, less analgesia and as a result a greater pain level. While the results of this study are consistent with that proposed mechanism, our data do not clarify whether increased morphine excretion leads to less anaesthesia and a higher arterial blood pressure or whether the primary change is an increase in blood pressure which secondarily produces improved urinary morphine excretion. Whichever may be the case, it appears that urinary morphine excretion influences respiratory dynamics in the early post-operative period after morphine anaesthesia and operation.

Our patients with TF had excreted only 33 per cent of their administered morphine two hours after operation and none had respiratory dynamics that would enable a safe extubation of the trachea until the day after operation. On the other hand, 55 per cent of patients with ASD were successfully extubated within six hours of their operation despite receiving a slightly higher dose of morphine than TF patients and sustaining a lower intraoperative blood loss and, therefore, presumably losing less morphine in the suction bottle. While there are obviously 
many other reasons why $\mathrm{TF}$ patients could have poorer post-operative respiratory dynamics than those with $A S D$, including a longer and more difficult operation, more post-operative hepatic dysfunction and therefore, impaired ability to conjugate morphine; greater embarrasment of the circulatory system pre- and postoperatively; a greater abnormality in respiratory dynamics pre-operatively (preoperative respiratory function studies were not done in patients in this study) and possibly a host of other factors, nevertheless renal excretion of morphine must also be considered.

The importance of renal function in dissipation of the respiratory effects of morphine is perhaps even easier to appreciate if consideration is limited to the patients with ASD in this study. Six children in this group excreted more urine and with it a greater percentage of their administered morphine than the other five children. In every other way the two sub-groups appeared similar. Those with the greater urinary output and morphine excretion were all extubated before 6 p.m. of the day of operation. Of the remainder, two were extubated four hours later, two six hours later and one each 10 and 12 hours afterwards.

The influence of morphine-3-glucuronide, and the minor metabolites normorphine and methyl-morphine (the latter were not determined in this study) on the medullary respiratory centre is not, to our knowledge, known. While it is generally assumed that metabolism of the opiate results in a complete dissipation of its pharmacological actions, ${ }^{3}$ this may not be so. Since only about 10 per cent of morphine is excreted unchanged and almost all of the remaining morphine excreted in the urine six to eight hours after intravenous administration of the drug is in the glucuronide conjugation form, it would appear that evaluation of the respiratory effects of this metabolite is warranted.

In conclusion, our data in this study demonstrate that reversal of the respiratory depressant effects of morphine is fostered by a vigorous urine output. These findings suggest, therefore, that in addition to use of a narcotic antagonist, stimulation of high urinary flow rates is a mechanism to diminish the pharmacological actions of morphine after morphine anaesthesia and operation.

\section{SUMMARY}

The urine of 20 children undergoing complete correction of atrial septal defect (ASD) or tetralogy of Fallot (TF) were analyzed for morphine and its glucuronide conjugation product before and after induction of morphine anaesthesia, throughout the operation and for two hours post-operatively. Children with ASD had a higher, mean urine flow rate during anesthetic induction and during the entire operation than those with TF $(\mathrm{P}<0.01)$. ASD children excreted a greater percentage of the administered morphine by the time they reached the recovery room and after two hours in the recovery room than those with TF. Urinary morphine in the glucuronide form increased progressively from anaesthetic induction until the post-operative period in both groups and was more than 93 per cent after two hours in the recovery room. Fifty-five per cent of ASD patients had respiratory dynamics that enabled them to be extubated within six hours of the end of their operation. Those that could be extubated after six hours had excreted 
a significantly greater percentage of morphine than those that couldn't $(\mathrm{P}<0.025)$. None of the children with TF could be extubated until the day after operation. These data demonstrate that the ability to maintain adequate spontaneous respiration after morphine anaesthesia is directly related to urinary output during anaesthesia and operation.

\section{RÉSUMÉ}

L'on a fait la détermination de la Morphine et de ses produits de dégradation dans l'urine avant, durant et après l'intervention (fermeture de C.I.A. ou correction de tétralogie de Fallot) chez 20 enfants âgés de 10 à 12 ans. Une fermeture de C.I.A. fut effectuée chez 11 des enfants qui reçurent en moyenne $3.4 \mathrm{mg}$ de Morphine par kilo. Chez les neuf autres enfants, l'on procéda à une correction de tétralogie de Fallot et la dose moyenne de Morphine utilisée fut de $2.9 \mathrm{mg} / \mathrm{kilo}$.

Par comparaison aux cas de tétralogie de Fallot, les enfants porteurs de C.I.A. ont présenté des débits urinaires supérieurs durant l'induction de l'anesthésie $(2 \mathrm{ml}$ vs $1.19 \mathrm{ml} /$ minute), et durant toute l'intervention ( 2.39 vs $1.08 \mathrm{ml} / \mathrm{minute}$ ). Ils avaient excrété un plus grand pourcentage de la Morphine administrée au moment de leur arrivée aux Soins Intensifs ( 54 pour cent vs 29 pour cent). Le pourcentage de Morphine urinaire sous forme conjugée augmentait graduellement durant l'intervention et attegnait 85 pour cent chez tous les enfants à la fin de l'intervention et 93 pour cent deux heures après leur arrivée aux Soins Intensifs.

Cinquante-cinq pour cent des porteurs de C.I.A. ont pu être extubés moins de six heures après l'intervention et ces enfants présentaient tous un taux d'excrétion urinaire de la Morphine plus élevé (significativement, $\mathrm{p}<0.025$ ) que ceux qui ont dû être laissé intubés plus de six heures. Aucun des malades ayant subi une correction de tétralogie de Fallot n'a pu être extubé avant le lendemain de l'intervention. Nos travaux indiquent que le retour à une ventilation adéquate après une anesthésie à la Morphine est en relation directe avec son excrétion urinaire en cours d'anesthésie et d'intervention.

\section{REFERENCES}

1. Wallace, J.E., Hamilton, H.E., Blum, K., \& Petty, C. Determination of morphine in biologic fluids by electron capture gas-liquid chromatography. Anal. Chem. 46: 2107 (1974).

2. YEH, S.Y. Urinary excretion of morphine and its metabolites in morphine-dependent subjects, J. Pharmacol. Exp. Ther. 192: 201 (1975).

3. Bnunk, S.F., Delle, M., \& Wilson, W.R. Morphine metabolism in man: Effect of aspirin. Clin. Pharmacol. Therapeut. 15: 283 (1974).

4. Stanley, T.H., Liv, W.S., \& Lathrop, G.D. The effects of morphine and halothane anaesthesia on urine norepinephrine during surgery for congenital heart disease. Canad. Anaesth. Soc. J. 23: 58 (1976). 